\section{BMJ Paediatrics Open}

\title{
Oxygen saturation after birth in resuscitated neonates in Uganda: a video-based observational study
}

\author{
Mårten Larsson (D) ,' Susanna Myrnerts Höök (D) ,,3,4 Allan Mpamize, ${ }^{5}$ \\ Thorkild Tylleskär (D) , ${ }^{2}$ Clare Lubulwa, ${ }^{5}$ Daniele Trevisanuto (D) , \\ Kristina Elfving (D) , ${ }^{1,7}$ Nicolas J Pejovic (D) 2,3,4
}

To cite: Larsson M, Myrnerts Höök S, Mpamize A, et al. Oxygen saturation after birth in resuscitated neonates in Uganda: a video-based observational study. BMJ Paediatrics Open 2022;6:e001225. doi:10.1136/ bmjpo-2021-001225

- Additional supplemental material is published online only. To view, please visit the journal online (http://dx.doi.org/ 10.1136/bmjpo-2021-001225).

Received 13 July 2021 Accepted 8 December 2021

\section{Check for updates}

C Author(s) (or their employer(s)) 2022. Re-use permitted under CC BY-NC. No commercial re-use. See rights and permissions. Published by BMJ.

For numbered affiliations see end of article.

Correspondence to Dr Susanna Myrnerts Höök; susanna.hook@uib.no

\section{ABSTRACT}

Background Monitoring of peripheral capillary oxygen saturation $\left(\mathrm{SpO}_{2}\right)$ during neonatal resuscitation is standard of care in high-resource settings, but seldom performed in low-resource settings. We aimed to measure $\mathrm{SpO}_{2}$ and heart rate during the first $10 \mathrm{~min}$ of life in neonates receiving positive pressure ventilation (PPV) according to the Helping Babies Breathe (HBB) protocol and compare results with $\mathrm{SpO}_{2}$ and heart rate targets set by the American Heart Âssociation (AHA).

Methods A cross-sectional study was conducted at Mulago National Referral Hospital, Kampala, Uganda, as a substudy of the NeoSupra Trial. $\mathrm{SpO}_{2}$ and heart rate were measured on apnoeic neonates ( $\geq 34$ weeks) who received PPV according to HBB (room air). Those who remained distressed after PPV received supplemental oxygen $\left(\mathrm{O}_{2}\right)$. All resuscitations were video recorded and data were extracted by video review at $1 \mathrm{~min}$ intervals until $10 \mathrm{~min}$ post partum. Data were analysed for all observations and separately for only observations before and during PPV. Results 49 neonates were analysed. Median $\mathrm{SpO}_{2}$ at $5 \mathrm{~min}(\mathrm{n}=39)$ was $67 \%(49-88)$ with $59 \%$ of the observations below AHA target of $80 \%$. At 10 min median $\mathrm{SpO}_{2}(\mathrm{n}=44)$ was $93 \%(80-97)$ and $32 \%$ were below AHA target of $85 \%$. When only observations before and during $\mathrm{PPV}$ were analysed, median $\mathrm{SpO}_{2}$ at $5 \mathrm{~min}(\mathrm{n}=18)$ was $52 \%(34-66)$ and $83 \%$ were below AHA target. At $10 \mathrm{~min}$ $(\mathrm{n}=15)$, median $\mathrm{SpO}_{2}$ was $72 \%(57-89)$ and $67 \%$ were below AHA target. Median heart rates were above AHA target of 100 beats/min at all time intervals.

Conclusions A high proportion of neonates resuscitated with PPV after birth failed to reach the $\mathrm{AHA} \mathrm{SpO}{ }_{2}$ target in this small sample, implying an increased risk of hypoxicischaemic encephalopathy. Further studies in low-resource settings are needed to evaluate baseline data and the need for supplemental $\mathrm{O}_{2}$ and optimal $\mathrm{SpO}_{2}$ during PPV.

Trial registration number This is a substudy to the trial 'Neonatal Resuscitation with Supraglottic Airway Trial (NeoSupra)'; ClinicalTrials. gov Registry (NCT03133572).

\section{INTRODUCTION}

Each year, 7 million neonates need positive pressure ventilation (PPV) after birth. ${ }^{1}$ In 2015, 700000 died of birth asphyxia, nearly half in sub-Saharan Africa. ${ }^{2}$

\section{What is known about the subject?}

Oxygen saturation $\left(\mathrm{SpO}_{2}\right)$ targets after birth for healthy neonates have been defined by the American Heart Association (AHA).

- There have been few studies in low-resource countries measuring $\mathrm{SpO}_{2}$ in asphyxiated neonates.

\section{What this study adds?}

Measurement of $\mathrm{SpO}_{2}$ during neonatal resuscitation with video-based observation in a hospital setting in sub-Saharan Africa.

- A high proportion of neonates resuscitated with positive pressure ventilation after birth failed to reach the AHA SpO ${ }_{2}$ targets in a Ugandan hospital.

In term and late preterm neonates, PPV should be initiated using room air instead of $100 \%$ oxygen, ${ }^{134}$ since there is a significant reduction in short-term mortality. ${ }^{5}$ Pulse oximetry is recommended to guide oxygen therapy and maintain oxygen saturation $\left(\mathrm{SpO}_{2}\right)$ within the normal ranges. ${ }^{346}$ This practice is supported by clinical consensus, but there is a paucity of studies assessing $\mathrm{SpO}_{2}$ during PPV in term infants. ${ }^{378}$ In low-resource settings, availability of blended oxygen and pulse oximetry is scarce and not included in guidelines aimed for this context, ${ }^{9}$ such as Helping Babies Breathe (HBB). ${ }^{10}$

Feasibility to reach $\mathrm{SpO}_{2}$ targets has been described among resuscitated neonates $<32$ weeks' gestational age and found to be mostly outside of target ranges. ${ }^{11}{ }^{12}$ For neonates $>32$ weeks, the feasibility of reaching targets is unknown. ${ }^{8}$ In 2007, Saugstad et al published a report on $\mathrm{SpO}_{2}$ in asphyxiated neonates receiving room air or $100 \%$ oxygen and described $\mathrm{SpO}_{2}$ levels in parity with current targets. ${ }^{13}{ }^{14} \mathrm{~A}^{2}$ study from Kathmandu, comparing early versus late cord clamping in 
late preterm and term resuscitated neonates, reported $\mathrm{SpO}_{2}$ levels below American Heart Association (AHA) target range. ${ }^{15}$ To our knowledge, that is the only study assessing $\mathrm{SpO}_{2}$, conducted in a low-resource setting, using the $\mathrm{HBB}$ protocol, where no oxygen during PPV was provided.

This study aimed to investigate $\mathrm{SpO}_{2}$ and heart rate in the first 10 min after birth in neonates who received PPV according to the HBB protocol in a high-volume hospital in sub-Saharan Africa and compare results with $\mathrm{SpO}_{2}$ and heart rate targets set by the AHA.

\section{METHODS}

\section{Study design, setting and population}

This cross-sectional observational study was conducted in January-July 2019 as a substudy of the NeoSupra Trial at the Mulago National Referral Hospital, Uganda, the largest public hospital in Kampala (altitude of $1200 \mathrm{~m}$ above sea level) with approximately 25000 births each year. ${ }^{16}{ }^{17}$ Most deliveries at this hospital present as emergencies, such as severe obstructed labour, fetal distress, antepartum haemorrhage or severe pre-eclampsia.

Resuscitations were performed by midwives trained in HBB and indication for PPV was apnoea or gasping. The attending research physician could intervene and supervise the resuscitation if needed, still following HBB. Oxygen was not provided during PPV according to the HBB protocol. ${ }^{18}$ After termination of PPV, neonates could receive oxygen by nasal cannula $0.5-5 \mathrm{~L} / \mathrm{min}$ if showing breathing difficulties and cyanosis at midwifes' discretion, according to hospital guidelines. Both neonates born through caesarean section (CS) in the operation theatre and by vaginal delivery in the labour ward were included by convenience when a research physician was available. Inclusion criteria were inborn neonates, estimated gestational age $\geq 34$ weeks, estimated birth weight $\geq 2000 \mathrm{~g}$, need for PPV at birth and parental consent. Exclusion criteria were any major malformation, incompatible with sustained life or affecting the airways, and stillbirth.

\section{Study procedure}

Immediately after birth, neonates eligible for inclusion had their cord cut and were taken to the resuscitation table where drying, stimulation, suctioning and PPV were initiated by a midwife. The research physician, who attended all births included in this substudy, placed a pulse oximeter probe (Philips reusable M1193A neonatal wrap sensor) on the neonate's right hand as soon as possible and connected it to a pulse oximeter (Philips Intellivue X2, Amsterdam, The Netherlands). Heart rate was measured by dry-electrode ECG NeoBeat Newborn HR Meter (Laerdal, Stavanger, Norway), ${ }^{19}$ which was also placed as soon as possible after the neonate arrived on the resuscitation table. All cases were video-recorded using an HD1080P Black Box AI-IP018 camera (Shenzen Aishine Electronics Co, China). $\mathrm{SpO}_{2}$ and heart rate were measured during the first $10 \mathrm{~min}$ after birth. Time of birth, time from birth to table, amniotic fluid appearance, Apgar score, and mother and neonate clinical characteristics were collected and recorded by research assistants on-site.

Video recordings were reviewed by an investigating physician. $\mathrm{SpO}_{2}$, heart rate, and signal quality were visually observed on video and registered every minute for $10 \mathrm{~min}$ after birth. If data could not be acquired at the predetermined time interval because of a hidden display or unsatisfactory signal quality, the data point was collected at a time span of $\pm 5 \mathrm{~s}$ from the determined time interval. If no data could be collected within this time span, it was registered as missing data. $\mathrm{SpO}_{2}$ signal was considered reliable if signal quality indicator showed medium-quality signal or better, if the plethysmograph curve showed continuous uniform waves of at least peakto-peak amplitude of $50 \%$ between the top and bottom line or if heart rate on pulse oximeter and ECG were congruent within a range of 5 beats per minute (bpm). When heart rate by ECG was not available, heart rate measurements from pulse oximeter were used. The ECG signal quality was considered reliable if numbers were seen with sharp background on the display and unreliable if background was blurred. Observations from video review were manually entered into an Excel (Microsoft, Redmond, Washington, USA) spreadsheet.

\section{Outcome}

Outcome measures were $\mathrm{SpO}_{2}$ and heart rate in the first $10 \mathrm{~min}$ after birth, and the proportion of neonates with $\mathrm{SpO}_{2}$ below the AHA target at 5 and 10 min after birth. The outcome measures were assessed for all observations and separately in the subgroup of observations before and during PPV at each time point.

AHA states the following preductal $\mathrm{SpO}_{2}$ ranges after birth: $1 \mathrm{~min} 60 \%-65 \%, 2 \mathrm{~min} 65 \%-70 \%, 3 \mathrm{~min}$ $70 \%-75 \%, 4 \mathrm{~min} 75 \%-80 \%, 5 \mathrm{~min} 80 \%-85 \%$ and at 10 min $85 \%-95 \%,{ }^{3}$ based on studies in healthy term neonates. ${ }^{6}$

\section{Patient and public involvement}

Neither patients nor the public were involved in design, or conduct, or reporting or dissemination plans of the study.

\section{Data analysis}

Since this was an explorative study, a priori sample size calculation was not performed but a sample of approximately 50 neonates was estimated sufficient to obtain representative data. Data analysis included video observations on $\mathrm{SpO}_{2}$ and heart rate with reliable signal quality available at each minute interval. Data were presented as numbers and proportions for categorical variables, means and SDs for normally distributed continuous variables, and medians and IQR for variables with skewed distribution. GraphPad-Prism V.9 (GraphPad Software, San Diego, California, USA) was used for statistical analysis and graphs. A subanalysis was made including only 
Table 1 Maternal and neonatal characteristics and data from the main study NeoSupra Trial ${ }^{*}$

\begin{tabular}{|c|c|c|}
\hline Characteristics & $\begin{array}{l}\mathrm{SpO}_{2} \text { study } \\
\mathrm{N}=49\end{array}$ & $\begin{array}{l}\text { NeoSupra Trial* } \\
\text { FM group } \\
\mathrm{N}=597\end{array}$ \\
\hline $\begin{array}{l}\text { Median maternal age, } \\
\text { years (IQR) }\end{array}$ & $24(21-28)$ & $23(20-28)$ \\
\hline $\begin{array}{l}\text { Amniotic fluid-meconium } \\
\text { stained, foul smelling or } \\
\text { both, } n(\%)\end{array}$ & $36(73)$ & $370(62)$ \\
\hline Caesarean section, n (\%) & $41(84)$ & $301(50)$ \\
\hline $\begin{array}{l}\text { Median birth weight, g } \\
\text { (IQR) }\end{array}$ & 3100 (2800-3300) & $3100(2800-3400)$ \\
\hline Male sex, $\mathrm{n}(\%)$ & $32(65)$ & $349(59)$ \\
\hline \multicolumn{3}{|l|}{ Median Apgar score, (IQR) } \\
\hline $1 \mathrm{~min}$ & $3(2-4)$ & $3(2-4)$ \\
\hline $5 \mathrm{~min}$ & $6(4-6)$ & $5(4-6)$ \\
\hline $10 \mathrm{~min}$ & $7(6-8)$ & $7(6-8)$ \\
\hline
\end{tabular}

${ }^{*}$ Pejovic et al. ${ }^{17}$

$\mathrm{FM}$, face mask; $\mathrm{SpO}_{2}$, peripheral capillary oxygen saturation.

observations before and during PPV at each minute interval. Proportions of neonates with $\mathrm{SpO}_{2}$ below target ranges at $5 \mathrm{~min}$ and $10 \mathrm{~min}$ after birth were calculated for both groups. Heart rate of $\geq 100 \mathrm{bpm}$ was considered as an indicator of adequate ventilation. ${ }^{34}$

\section{RESULTS}

\section{Neonatal characteristics}

Sixty-eight neonates were initially selected for inclusion, of which 19 were later excluded. Reasons for exclusion were: one stillbirth; one declined verbal consent and three resuscitations that were not captured on video. Fourteen neonates were excluded since $\mathrm{SpO}_{2}$ data from the video recordings were unavailable due to late positioning of the pulse oximeter probe, difficulty to see oximeter display on video or unreliable $\mathrm{SpO}_{2}$ signal quality. The final dataset included 49 neonates.

Neonatal and maternal characteristics are reported in table 1, together with data from the face mask (FM) group of the main study, NeoSupra Trial. ${ }^{17}$ Apgar score at 5 min was $<5$ in $30 \%$ of neonates and $<7$ in $76 \%$. Seventy-three per cent presented meconium-stained or foul-smelling amniotic fluid. Time to achieve first $\mathrm{SpO}_{2}$ measurement was $163 \mathrm{~s}$ (IQR 132-222) and PPV was started within the first minute in five neonates $(10 \%)$. Supplemental oxygen was administered to 21 neonates after PPV (due to difficulty of breathing or cyanosis). Ten neonates $(20 \%)$ died in the first week of life out of which six died after resuscitation in the delivery room (table 2 ).

In the FM group of the NeoSupraTrial, $89 \%$ ( $n=530$ of 597) of neonates were hospitalised and $11 \%$ ( $\mathrm{n}=67$ of 597 ) died after resuscitation; $18 \%$ ( $\mathrm{n}=109$ of 597) were found dead at 7-day follow-up.

As there were no reliable $\mathrm{SpO}_{2}$ observations in the first minute after birth, data referred to this time point were
Table 2 Delivery room interventions, hospitalisation and clinical outcome

\begin{tabular}{|c|c|}
\hline & $\mathrm{N}=49$ \\
\hline Median time from birth* to table, s (IQR) & $31(25-41)$ \\
\hline $\begin{array}{l}\text { Median time from birth* to first } \mathrm{SpO}_{2} \text { data, } \\
\mathrm{n}=46, \mathrm{~s}(\mathrm{IQR})\end{array}$ & $163(132-222)$ \\
\hline $\begin{array}{l}\text { Median time from birth* to first HR data, } \\
\text { ECG†, } n=45, s(I Q R)\end{array}$ & $93(69-139)$ \\
\hline $\begin{array}{l}\text { Median time from birth }{ }^{*} \text { to first HR data, } \\
P O x, n=48, s(I Q R)\end{array}$ & $188(138-237)$ \\
\hline $\begin{array}{l}\text { Median time from birth* to start of } \\
\text { ventilation, } s(I Q R)\end{array}$ & $123(93-157)$ \\
\hline Median duration of ventilation, s (IQR) & $179(98-626)$ \\
\hline $\begin{array}{l}\text { Median time from birth* to start of } \\
\text { supplemental } \mathrm{O}_{2}, \mathrm{n}=21, \mathrm{~s}(\mathrm{IQR})\end{array}$ & $331(291-399)$ \\
\hline LMA resuscitation, $\mathrm{n}(\%)$ & $17(35)$ \\
\hline Oxygen supplementation after PPV, n (\%) & $21(43)$ \\
\hline $\begin{array}{l}\text { Neonates received ventilation within first } \\
\text { minute, } \mathrm{n}(\%)\end{array}$ & $5(10)$ \\
\hline $\begin{array}{l}\text { Switch from face mask to LMA during first } \\
10 \mathrm{~min}, \mathrm{n}(\%)\end{array}$ & $2(4)$ \\
\hline $\begin{array}{l}\text { Advanced resuscitation } \ddagger \text { during first } \\
10 \mathrm{~min}, \mathrm{n}(\%)\end{array}$ & $1(2)$ \\
\hline $\begin{array}{l}\text { Hospitalised directly after resuscitation, } n \\
(\%)\end{array}$ & 42 (86) \\
\hline Death after resuscitation, $\mathrm{n}(\%)$ & $6(12)$ \\
\hline $\begin{array}{l}\text { Total mortality at 7-day follow-up, } n(\%) \text {, } \\
n=48\end{array}$ & $10(20)$ \\
\hline
\end{tabular}

${ }^{*}$ Time of birth was defined as the time when the entire neonate had exited the mother's body.

†Measured by dry-electrode ECG.

¥Endotracheal intubation (only possible if investigating neonatologist present), chest compressions or both. $\mathrm{HR}$, heart rate; LMA, laryngeal mask airway; $\mathrm{O}_{2}$, oxygen; POx, pulse oximeter; PPV, positive pressure ventilation; $\mathrm{SpO}_{2}$, peripheral capillary oxygen saturation.

excluded from analysis (figure 1). Missing $\mathrm{SpO}_{2}$ data were more frequent at early time intervals and due to late attachment of the pulse oximeter probe and unreliable $\mathrm{SpO}_{2}$ signal quality (figure 1). Heart rate observations were also mostly missing the first minutes due to late positioning of pulse oximeter and ECG probes or bad signal quality (figure 2).

\section{All observations}

$\mathrm{SpO}_{2}$ values from 2 to $10 \mathrm{~min}$ after birth are shown in figure $1 \mathrm{~A}$. When analysing all observations, median $\mathrm{SpO}_{2}$ level was below AHA target from 2 to 5 min after birth (figure 1A). At $5 \mathrm{~min}$ after birth, $59 \%$ of all neonates $(\mathrm{n}=39)$ had $\mathrm{SpO}_{2}$ values below the AHA target, and at $10 \mathrm{~min}(\mathrm{n}=44)$ the proportion was $32 \%$ (table 3$)$. Of the 21 neonates receiving oxygen supplementation because of difficulty of breathing after PPV, seven (33\%) had $\mathrm{SpO}_{2}$ above AHA target range $(85 \%-95 \%)$ at $10 \mathrm{~min}$. 
A

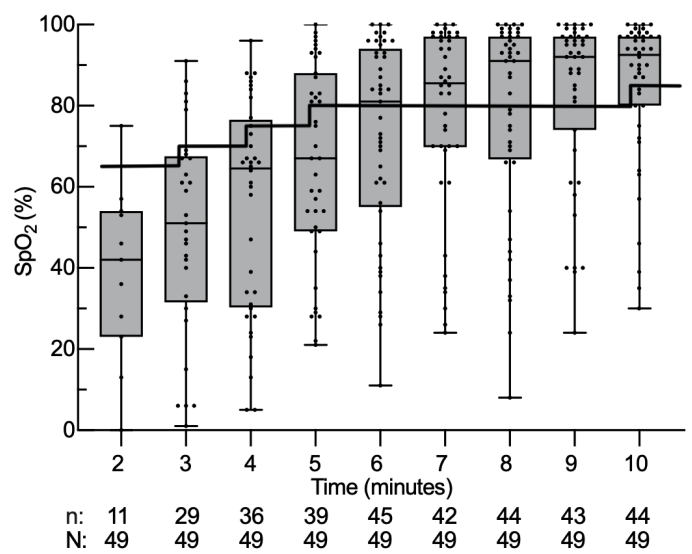

B

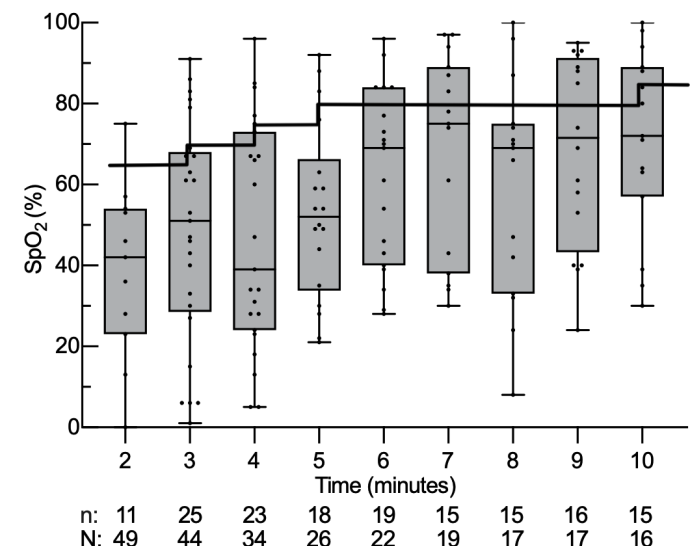

- American Heart Association lower limit of $\mathrm{SpO}_{2}$ target range

Figure 1 Preductal peripheral capillary oxygen saturation $\left(\mathrm{SpO}_{2}\right)$ by pulse oximetry at 2-10 min after birth presented as box plots showing the median, quartiles, range ( $\mathrm{min}$ and max values) and individual data points. Observations obtained $(\mathrm{n})$ and sample size (N) are shown below the graph. (A) $\mathrm{SpO}_{2}$ observations of all neonates at each time point. (B) $\mathrm{SpO}_{2}$ observations of neonates before and during positive pressure ventilation at each time point.

A post hoc analysis was made separating the 36 neonates with meconium-stained, foul-smelling amniotic fluid or both from those 13 neonates with clear amniotic fluid. In the meconium group, median $\mathrm{SpO}_{2}$ at 5 min was $79 \%$ (IQR 50-88, $\mathrm{n}=26$ ) and 50\% were below AHA target. At 10 min, median $\mathrm{SpO}_{\text {o }}$ was $94 \%$ (IQR 86-97, $\mathrm{n}=31$ ) and $26 \%$ were below AHA target. In the group with clear amniotic fluid, median $\mathrm{SpO}_{2}$ at 5 min was $57 \%$ (IQR 46-68, $\mathrm{n}=12$ ) and $75 \%$ were below AHA target. At $10 \mathrm{~min}$, median $\mathrm{SpO}_{2}$ was $84 \%$ (IQR 59-95, $\mathrm{n}=12$ ) and $50 \%$ were below AHA target.

\section{Observations before and during PPV}

When only observations before and during PPV were included in the analysis, the median $\mathrm{SpO}_{2}$ was below AHA target at all time intervals (figure 1B). The proportion of neonates with $\mathrm{SpO}_{2}$ below AHA target at 5 min after birth was $83 \%(\mathrm{n}=18)$ and at $10 \mathrm{~min} 67 \%(\mathrm{n}=15)$ (table 3$)$.

\section{Heart rate}

Median heart rate was above target of $100 \mathrm{bpm}$ at each minute interval for both all observations and only observations before and during PPV (figure 2A,B). At 2 min, 12 observations were below target in both groups and decreased every minute thereafter. At 10 min, no observations were below this target.

\section{DISCUSSION}

In this observational study, a high proportion of resuscitated neonates had $\mathrm{SpO}_{2}$ values below AHA target in the

$$
\text { A }
$$

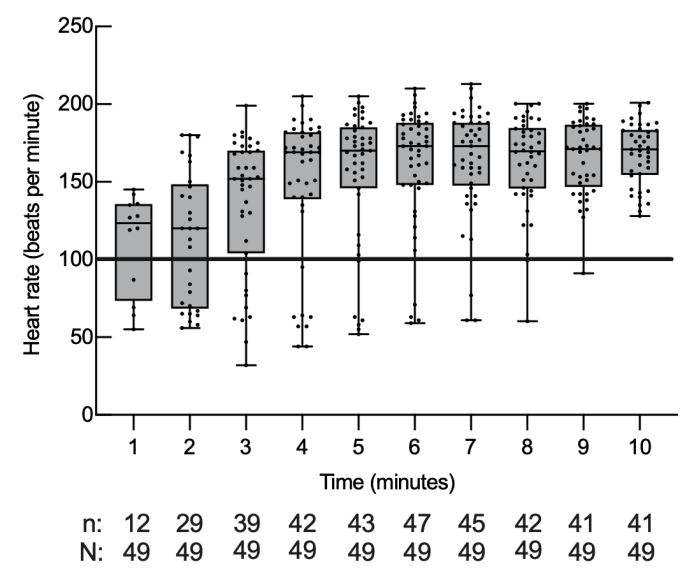

B

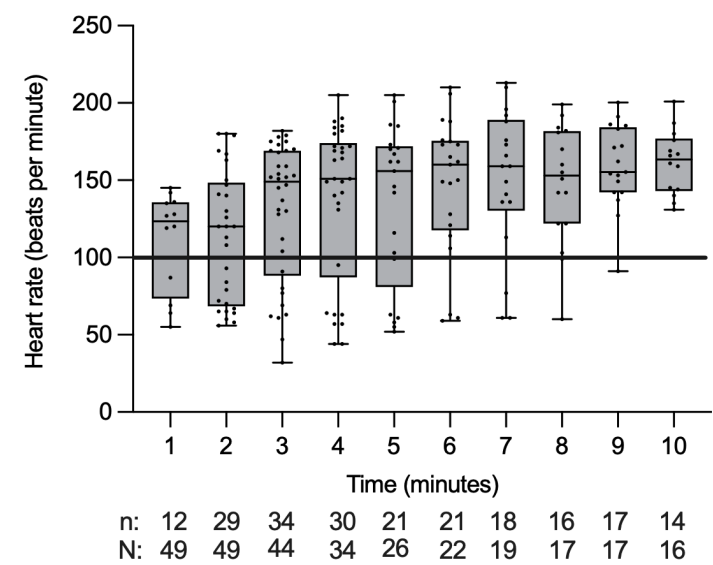

American Heart Association heart rate target

Figure 2 Heart rate measured by dry-electrode ECG or pulse oximetry at 1-10 min after birth presented as box plots showing the median, quartiles, range (min and max values) and individual data points. Observations obtained $(\mathrm{n})$ and sample size $(\mathrm{N})$ are shown below the graph. (A) Heart rate observations of all neonates at each time point. (B) Heart rate observations of neonates before and during positive pressure ventilation at each time point. 
Table $3 \mathrm{SpO}_{2}$ values and proportion of neonates with $\mathrm{SpO}_{2}$ below American Heart Association (AHA) target

\begin{tabular}{lllll}
\hline & \multicolumn{2}{l}{ All observations } & \multicolumn{2}{l}{ Observations before and during positive pressure ventilation } \\
\hline Time after birth & $5 \mathrm{~min}$ & $10 \mathrm{~min}$ & $5 \mathrm{~min}$ & $10 \mathrm{~min}$ \\
\hline Observations, $\mathrm{n}$ & 39 & 44 & 18 & 15 \\
Median $\mathrm{SpO}_{2}$ (IQR) & $67(49-88)$ & $93(80-97)$ & $52(34-66)$ & $72(57-89)$ \\
Observations below $_{\mathrm{AHA} \mathrm{SpO}}$ target, $\mathrm{n}(\%)$ & $23(59)$ & $14(32)$ & $15(83)$ & $10(67)$
\end{tabular}

$\mathrm{SpO}_{2}$, peripheral capillary oxygen saturation.

first 10 min after birth, while heart rate remained above $100 \mathrm{bpm}$ for the most part of the measurements.

The strengths of the present study include (1) data collection from review of video recordings allowing detailed monitoring of observed parameters, signal quality and hence enhanced reliability of data ${ }^{20}$; ; (2) the assessment of $\mathrm{SpO}_{2}$ and heart rate in a low-resource setting where PPV is performed in room air without the $\mathrm{SpO}_{2}$ monitoring.

Few studies have observed $\mathrm{SpO}_{2}$ during neonatal resuscitation. In a study by Saugstad et al, median $\mathrm{SpO}_{2}$ in neonates resuscitated with room air was $90 \%$ (5th-95th percentile 66-95, $\mathrm{n}=100)$ at $5 \mathrm{~min}$ and $90 \%$ (83-96, $\mathrm{n}=110$ ) at $10 \mathrm{~min}$, median Apgar score 4, 7 and 8 at 1 , 5 and $10 \mathrm{~min}$, respectively. ${ }^{13}$ Our corresponding figures were $67 \%$ (IQR 49-88) and 93\% (80-97). Reasons for lower saturation at $5 \mathrm{~min}$ could be quality of resuscitation, observational method or severity of the asphyxia. Three-quarters of neonates in this study had Apgar score $<7$ at $5 \mathrm{~min}$, associated with increased risk of mortality and morbidity. ${ }^{22-24} \mathrm{In} \mathrm{Nepal}$, mean $\mathrm{SpO}_{2}$ levels in an early cord clamping group who received PPV $(n=45)$ were $76.1 \%$ (SD 3.9) at $5 \mathrm{~min}$ and $85.1 \%$ (SD 2.8) at $10 \mathrm{~min}$. $\mathrm{SpO}_{2}$ at 10 min was somewhat lower than in our study and results were also below the AHA targets. ${ }^{15}$ In both studies, $\mathrm{SpO}_{2}$ data were collected by direct observation and not by video review. $\mathrm{SpO}_{2}$ in neonates at high altitude $(>4000 \mathrm{~m}$ above sea level) has been shown to be lower compared with measurements at sea level. ${ }^{25}$ Another study at similar altitude as Kampala observed comparable $\mathrm{SpO}_{2}$ at birth with the reference study at sea level by Dawson et al (median $69 \%$ vs $66 \%$ at $1 \mathrm{~min}$ ), and we assume the altitude had a minor impact on our results. ${ }^{6} 26$

The high $\mathrm{SpO}_{2}$ dispersion reflects the variability of illness in resuscitated neonates. In our study, $43 \%$ of the neonates received oxygen after PPV (upon midwives' assessment of breathing difficulties or cyanosis). This probably increased median $\mathrm{SpO}_{2}$, especially from 5 min after birth. Still, large proportions of patients $(59 \%$ at $5 \mathrm{~min}, 32 \%$ at $10 \mathrm{~min}$ ) had an $\mathrm{SpO}_{2}$ below AHA target. When only neonates before and during PPV were analysed, the proportion was even more prominent $(83 \%$ at $5 \mathrm{~min}, 67 \%$ at $10 \mathrm{~min}$ ) (table 3 ). Yet, most neonates had heart rate above $100 \mathrm{bpm}$, which is considered a sign of adequate ventilation (figure 2). ${ }^{3}{ }^{4}$ This suggests that adequate PPV alone is not sufficient to achieve $\mathrm{SpO}_{2}$ in the recommended range. Though, since no respiratory function monitoring was used, conclusions about adequacy of PPV is not possible to make. This study observed a large portion of neonates with either meconium-stained, or foul-smelling amniotic fluid, or both indicating meconium aspiration. This could theoretically explain the low $\mathrm{SpO}_{2}$ in this sample, but a post hoc analysis surprisingly showed higher $\mathrm{SpO}_{2}$ in the group with meconium-stained amniotic fluid. A finding hard to interpret, but high rate of missing data in the meconium group and the small sample size are possible explanations. Persistent hypoxia in asphyxiated neonates may exacerbate pulmonary hypertension and have shortterm and long-term consequences of hypoxic-ischaemic encephalopathy. ${ }^{27}$ Oxygen is not included in the HBB algorithm, since it is scarce and difficult to administer in blended form in low-income contexts, ${ }^{10}{ }^{28}$ but the availability of oxygen in sub-Saharan African hospitals is increasing. ${ }^{29}{ }^{30}$ A neonatal resuscitation algorithm for low-resource and middle-resource settings that includes oxygen has been proposed. ${ }^{31}$ The present study might support its use. Nevertheless, preventing dangerous hyperoxia is also recommended ${ }^{347}$; of note, $33 \%$ of neonates receiving supplemental oxygen after PPV had $\mathrm{SpO}_{2}$ levels above target range $(>95 \%)$ at $10 \mathrm{~min}$. These findings suggest that $\mathrm{SpO}_{2}$ measurement would be considered also in low-resource settings because the agreement between the assessment of infant colour and $\mathrm{SpO}_{2}$ is limited. ${ }^{32}$

The questions regarding supplemental oxygen still remain: oxygen or not, when and how much? Our results raise the question if these neonates would benefit from supplemental $\mathrm{O}_{2}$ during PPV. However, transferring a practice from one context to another may have detrimental effects. ${ }^{33}$ Caution must be taken not to implement an advanced resuscitation algorithm before the basic skills of good quality PPV have been mastered. Safe and accessible devices to blend and titrate oxygen need to be available as well as $\mathrm{SpO}_{2}$ monitoring to avoid both hypoxia and hyperoxia. Optimal saturation and oxygenation for neonates in need of PPV needs to be further investigated. ${ }^{78}$

This study has some limitations. It was an exploratory investigation with a limited number of participants which prevented calculations of $\mathrm{CI}$ and hence results can be difficult to generalise. Neonates were selected by convenience sampling based on the research physician's availability, with risk for selection bias. However, baseline characteristics were 
in broad agreement with the NeoSupra Trial (table 1). ${ }^{17}$ Of note, the observed high rate of CS $(84 \%)$ was partly due to convenience sampling but also due to lack of oximeter visibility on video recordings from the labour ward resuscitation table, where vaginal deliveries were performed. This was one of the main reasons for exclusion of neonates initially selected for analysis. Dawson et al reported that healthy babies born by CS are known to have lower $\mathrm{SpO}_{2}$ compared with those by vaginal delivery. ${ }^{6}$ It is difficult to assess if the high rate of CS affected the results in these severely asphyxiated neonates. This observational study suffered from missing $\mathrm{SpO}_{2}$ and heart rate data, particularly immediately after birth. This seems to be a random data loss that would not affect the results but implies an uncertainty to the data, especially at the initial time intervals. Median time to start of ventilation (123s) in this study was markedly above the aimed for 'golden minute' (first minute of life), indicating difficulties in compliance with the HBB algorithm, mostly due to prolonged stimulation and suctioning. The delay in ventilation is a possible explanation of the low $\mathrm{SpO}_{2}$ in our study and it would be interesting to see if $\mathrm{SpO}_{2}$ improves with earlier start of ventilation. Time to PPV from birth in an earlier cohort at the same hospital was $137 \mathrm{~s}(\mathrm{n}=99)$ and $92 \mathrm{~s}$ $(\mathrm{n}=48)$ after $\mathrm{CS}$, indicating the problem is recurring. ${ }^{34}$ This is however not an issue unique to our study site. In a video observation study of 76 neonates from a hospital in Tanzania (where numerous HBB studies have been undertaken) that included rigorous $\mathrm{HBB}$ training, median time from birth to first ventilation was $108 \mathrm{~s}$ and the total duration of stimulation and suctioning before first ventilation was $45 \mathrm{~s} .{ }^{35} \mathrm{~A}$ study from Mozambique found similar delays in ventilation after training. ${ }^{36}$ These examples highlight the difficulty in reaching the HBB target in this setting and we believe our results might reflect the situation in other busy hospitals in sub-Saharan Africa.

\section{CONCLUSIONS}

A high proportion of neonates resuscitated with PPV after birth failed to reach the $\mathrm{AHA} \mathrm{SpO}_{2}$ target in this small sample, implying an increased risk for hypoxic-ischaemic encephalopathy. Further studies in low-resource settings are needed to evaluate baseline data and the need for supplemental $\mathrm{O}_{2}$ and optimal $\mathrm{SpO}_{2}$ during PPV with longterm follow-up on mortality and neurological outcome. ${ }^{8}$

\author{
Author affiliations \\ ${ }^{1}$ Paediatric Department, Queen Silvia's Hospital for Children and Young People, \\ Gothenburg, Sweden \\ ${ }^{2}$ Centre for International Health, University of Bergen Faculty of Medicine and \\ Dentistry, Bergen, Norway \\ ${ }^{3}$ Department of Global Public Health, Karolinska Institute, Stockholm, Sweden \\ ${ }^{4}$ Sachs' Children and Youth Hospital, Stockholm, Sweden \\ ${ }^{5}$ Mulago National Referral Hospital, Kampala, Uganda \\ ${ }^{6}$ Department of Women's and Children's Health, University of Padua, Padova, Italy \\ ${ }^{7}$ School of Public Health and Community Medicine, University of Gothenburg, \\ Gothenburg, Sweden
}

Twitter Susanna Myrnerts Höök @SavingNeonates
Acknowledgements We would like to give our greatest appreciation to the staff at the Maternity and Neonatal Special Care Unit of Mulago National Referral Hospital, Kampala, Uganda, for their wonderful work to improve the care of neonates. We want to give special thanks to Francesco Cavallin (Independent Statistician, Solagna, Italy) for his invaluable comments on the manuscript. We also want to thank Josaphat Byamugisha and Jolly Nankunda (both Mulago National Referral Hospital) for their important contribution to the study.

Contributors ML was responsible for the study design, data analysis, interpretation of data and contributed to preparation of the study site. He conducted the literature research and was responsible for the writing process of the manuscript and approval of the final draft. SMH contributed to study design and to the acquisition of data. She was responsible for preparation of the study site, revised the work draft, approved the final draft and act as guarantor of the study. AM was responsible for acquisition of data, contributed to preparation of the study site and approved the final draft. TT contributed to study design, revised the work draft and approved the final draft. CL contributed to study design, manuscript revision and approved the final draft. DT contributed to study design, interpretation of data, manuscript revision and approved the final draft. KE contributed to study design, data analysis and interpretation of data. She revised the work draft and approved the final draft. NJP contributed to study design, data analysis, interpretation of data and literature research. He was responsible for preparation of the study site, revised the work draft, approved the final draft and act as guarantor of the study.

Funding This was a substudy of the NeoSupra Trial supported by unrestricted grants from the Research Council of Norway (grant 250531) and the Centre for Intervention Science in Maternal and Child Health (project number 223269), Norway. Queen Silvia Children's Hospital, Paediatric Department contributed with a grant for the first author to work on the manuscript. In-kind contributions were made by the University of Bergen and Stavanger University Hospital, Norway; Makerere University, Uganda; Karolinska Institutet and Sachs' Children and Youth Hospital, Sweden; and Padua University, Italy.

Competing interests None declared.

Patient consent for publication Not required.

Ethics approval This study involves human participants and was part of the NeoSupra Trial, ${ }^{16}$ approved by the Institutional Review Board of Mulago National Referral Hospital, Uganda; the Uganda National Council of Science and Technology; the Director General from the Ministry of Health, Uganda (MREC 1168); and the Regional Committee for Medical and Health Research Ethics (REK South East reference number 2017/989) in Norway. A two-tier procedure for consent was used. All women admitted to the labour ward during the study period were given brief verbal information of the trial and provided oral consent. Written deferred consent was sought from mothers, whose neonates met inclusion criteria.

Provenance and peer review Not commissioned; externally peer reviewed.

Data availability statement Data are available upon reasonable request. All data relevant to the study are included in the article or uploaded as supplemental information. All original data for this substudy is available as a supplemental material. Background data can be made available upon reasonable request.

Supplemental material This content has been supplied by the author(s). It has not been vetted by BMJ Publishing Group Limited (BMJ) and may not have been peer-reviewed. Any opinions or recommendations discussed are solely those of the author(s) and are not endorsed by BMJ. BMJ disclaims all liability and responsibility arising from any reliance placed on the content. Where the content includes any translated material, BMJ does not warrant the accuracy and reliability of the translations (including but not limited to local regulations, clinical guidelines, terminology, drug names and drug dosages), and is not responsible for any error and/or omissions arising from translation and adaptation or otherwise.

Open access This is an open access article distributed in accordance with the Creative Commons Attribution Non Commercial (CC BY-NC 4.0) license, which permits others to distribute, remix, adapt, build upon this work non-commercially, and license their derivative works on different terms, provided the original work is properly cited, appropriate credit is given, any changes made indicated, and the use is non-commercial. See: http://creativecommons.org/licenses/by-nc/4.0/.

ORCID iDs

Mårten Larsson http://orcid.org/0000-0001-9142-8165

Susanna Myrnerts Höök http://orcid.org/0000-0001-7560-4077

Thorkild Tylleskär http://orcid.org/0000-0003-4801-4324

Daniele Trevisanuto http://orcid.org/0000-0002-6462-0079 
Kristina Elfving http://orcid.org/0000-0003-4477-8765

Nicolas J Pejovic http://orcid.org/0000-0001-9963-7375

\section{REFERENCES}

1 Wyckoff MH, Wyllie J, Aziz K, et al. Neonatal life support: 2020 international consensus on cardiopulmonary resuscitation and emergency cardiovascular care science with treatment recommendations. Circulation 2020;142.

2 Liu L, Oza S, Hogan D, et al. Global, regional, and national causes of under-5 mortality in 2000-15: an updated systematic analysis with implications for the sustainable development goals. Lancet 2016:388:3027-35.

3 Aziz K, Lee HC, Escobedo MB, et al. Part 5: neonatal resuscitation: 2020 American heart association guidelines for cardiopulmonary resuscitation and emergency cardiovascular care. Circulation 2020;142.

4 Madar J, Roehr CC, Ainsworth S, et al. European resuscitation Council guidelines 2021: newborn resuscitation and support of transition of infants at birth. Resuscitation 2021;161:291-326.

5 Welsford M, Nishiyama C, Shortt C, et al. Room air for initiating term newborn resuscitation: a systematic review with meta-analysis. Pediatrics 2019;143:15.

6 Dawson JA, Kamlin COF, Vento M, et al. Defining the reference range for oxygen saturation for infants after birth. Pediatrics 2010;125:e1340-7.

7 Saugstad OD, Oei J-L, Lakshminrusimha S, et al. Oxygen therapy of the newborn from molecular understanding to clinical practice. Pediatr Res 2019;85:20-9.

8 Gottimukkala SB, Sotiropoulos JX, Lorente-Pozo S, et al. Oxygen saturation (SpO2) targeting for newborn infants at delivery: are we reaching for an impossible unknown? Semin Fetal Neonatal Med 2021;26:101220.

9 Duke T, Graham SM, Cherian MN, et al. Oxygen is an essential medicine: a call for international action. Int $J$ Tuberc Lung Dis 2010;14:11:1362-8.

10 Kamath-Rayne BD, Thukral A, Visick MK, et al. Helping babies breathe, second edition: a model for strengthening educationa programs to increase global newborn survival. Glob Health Sci Pract 2018:6:538-51.

11 White LN, Thio M, Owen LS, et al. Achievement of saturation targets in preterm infants $<32$ weeks' gestational age in the delivery room. Arch Dis Child Fetal Neonatal Ed 2017;102:F423-7.

12 Phillipos E, Solevåg AL, Aziz K, et al. Oxygen saturation and heart rate ranges in very preterm infants requiring respiratory support at birth. J Pediatr 2017;182:41-6.

13 Saugstad OD, Ramji S, Rootwelt T. Response to resuscitation of the newborn: early prognostic variables: newborn resuscitation: early response and prognostic signs. Acta Paediatr 2005;94:890-5.

14 Saugstad OD, Rootwelt T, Aalen O. Resuscitation of asphyxiated newborn infants with room air or oxygen: an international controlled trial: the Resair 2 study. Pediatrics 1998;102:e1.

15 Andersson O, Rana N, Ewald U, et al. Intact cord resuscitation versus early cord clamping in the treatment of depressed newborn infants during the first 10 minutes of birth (Nepcord III) - a randomized clinical trial. Matern Health Neonatol Perinatol 2019;5:15.

16 Pejovic NJ, Myrnerts Höök S, Byamugisha J, et al. Neonatal resuscitation using a supraglottic airway device for improved mortality and morbidity outcomes in a low-income country: study protocol for a randomized trial. Trials 2019;20:444.
17 Pejovic NJ, Myrnerts Höök S, Byamugisha J, et al. A randomized trial of laryngeal mask airway in neonatal resuscitation. $N$ Engl J Med 2020;383:2138-47.

18 The American Academy of pediatrics 2016, helping babies breathe 2nd edition summary of changes. AAP.org. Available: http:// www.aap.org/en-us/advocacy-and-policy/aap-health-initiatives/ helping-babies-survive/Pages/Helping-Babies-Breathe-2nd-EditionSummmary-of-Changes.aspx [Accessed 1 Jul 2021].

19 Linde JE, Schulz J, Perlman JM, et al. Normal newborn heart rate in the first five minutes of life assessed by Dry-Electrode electrocardiography. Neonatology 2016;110:231-7.

20 Fishman CE, Weinberg DD, Murray A, et al. Accuracy of real-time delivery room resuscitation documentation. Arch Dis Child Fetal Neonatal Ed 2020;105:222-4

21 Schilleman K, Witlox RS, van Vonderen JJ, et al. Auditing documentation on delivery room management using video and physiological recordings. Arch Dis Child Fetal Neonatal Ed 2014;99:F485-90.

22 Casey BM, McIntire DD, Leveno KJ. The continuing value of the Apgar score for the assessment of newborn infants. N Engl J Med 2001;344:467-71.

23 Salustiano EMA, Campos JADB, Ibidi SM, et al. Low Apgar scores at 5 minutes in a low risk population: maternal and obstetrical factors and postnatal outcome. Rev Assoc Med Bras 2012;58:587-93.

24 Iliodromiti S, Mackay DF, Smith GCS, et al. Apgar score and the risk of cause-specific infant mortality: a population-based cohort study. Lancet 2014;384:1749-55

25 Gonzales GF, Salirrosas A. Arterial oxygen saturation in healthy newborns delivered at term in Cerro de PASCO (4340 M) and lima (150 M). Reprod Biol Endocrinol 2005;3:46.

26 Bakr AF, Habib HS. Normal values of pulse oximetry in newborns at high altitude. J Trop Pediatr 2005;51:170-3.

27 Moshiro R, Mdoe P, Perlman JM. A global view of neonatal asphyxia and resuscitation. Front Pediatr 2019;7:489.

28 Berkelhamer SK, Kamath-Rayne BD, Niermeyer S. Neonatal resuscitation in low-resource settings. Clin Perinatol 2016;43:573-91.

29 Belle J, Cohen H, Shindo N, et al. Influenza preparedness in lowresource settings: a look at oxygen delivery in 12 African countries. $J$ Infect Dev Ctries 2010;4:419-24.

30 Nakkazi E. Oxygen supplies and COVID-19 mortality in Africa Lancet Respir Med 2021:9:e39.

31 Umphrey L, Breindahl M, Brown A, et al. When helping babies breathe is not enough: designing a novel, Mid-Level neonatal resuscitation algorithm for Médecins sans Frontières field teams working in low-resource Hospital settings. Neonatology 2018;114:112-23.

32 Cavallin F, Cori MS, Negash S, et al. Limited agreement between clinical assessment of infant colour at birth and oxygen saturation in a hospital in Ethiopia. Acta Paediatr 2021;110:68-71.

33 Maitland K, Kiguli S, Opoka RO, et al. Mortality after fluid bolus in African children with severe infection. $N$ Engl J Med 2011;364:2483-95.

34 Helldén D, Myrnerts Höök S, Pejovic NJ, et al. Neonatal resuscitation practices in Uganda: a video observational study. BMJ Paediatr Open 2021;5:e001092.

35 Haug IA, Holte K, Chang CL, et al. Video analysis of newborn resuscitations after simulation-based helping babies breathe training. Clin Simul Nurs 2020;44:68-78.

36 Trevisanuto D, Bertuola F, Lanzoni P, et al. Effect of a neonatal resuscitation course on healthcare providers' performances assessed by video recording in a low-resource setting. PLoS One 2015;10:e0144443. 